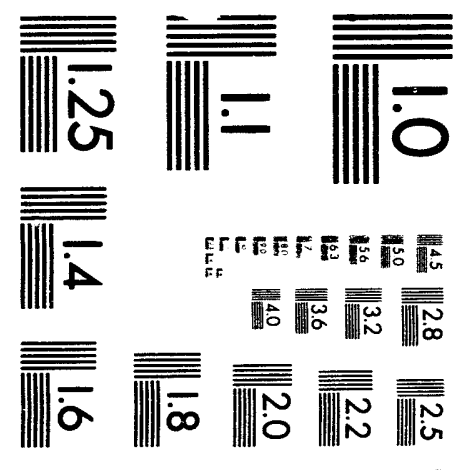



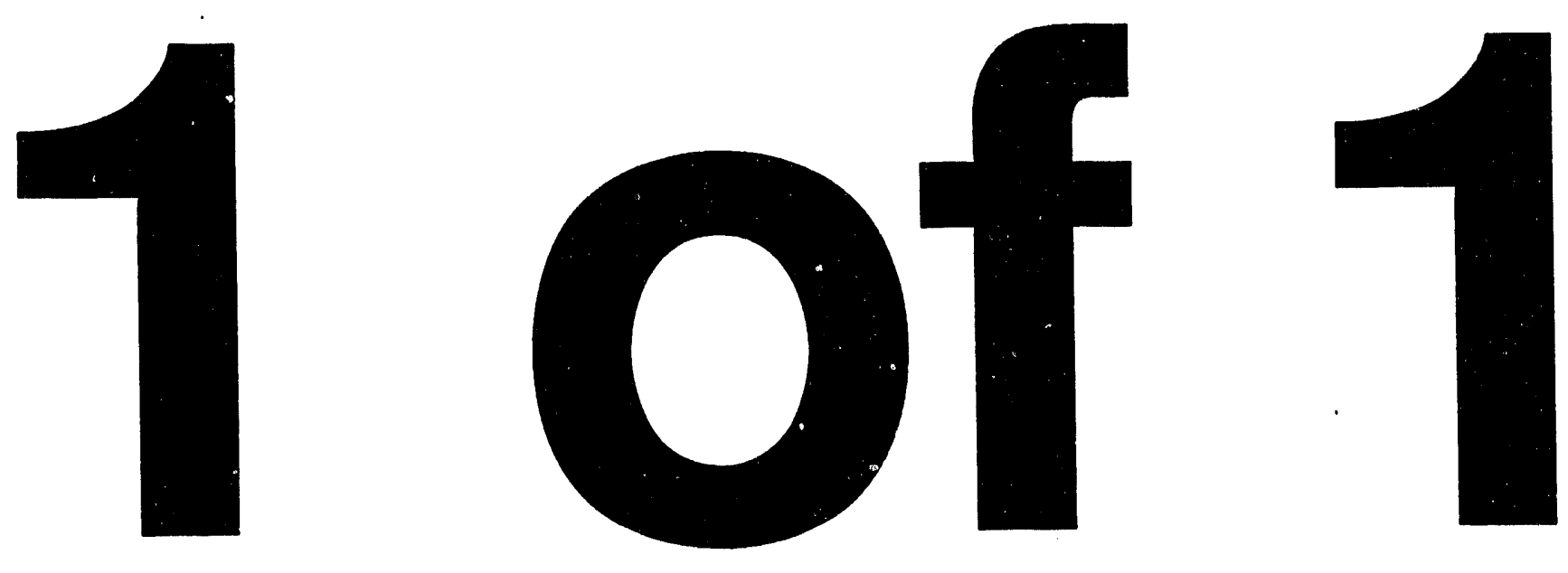


\title{
Effects of Oxide Charge and Surface Recombination Velocity on the Excess Base Current of BJTs
}

\author{
S.L. Kosier ${ }^{\dagger}$, R.D. Schrimpf ${ }^{\dagger}$, A. Wei ${ }^{\dagger}$, M. DeLaus*, \\ D.M. Fleetwood ${ }^{\#}$, and W.E. Combs ${ }^{\dagger \dagger}$
}

\begin{abstract}
The role of net positive oxide trapped charge and surface recombination velucity on excess base current in BJTs is identified. The effects of the two types of damage can be detected by plotting the excess base current versus base-enuitter voltage. Differences and similarities between ionizing-radiation-induced and hot electron-induced degradation are discussed.
\end{abstract}

\section{Introduction}

The current gain $l_{C} l_{B}$ of bipolar transistors is degraded when the uxide over the enulter-base junction is danaged. This carn occur when the emitter-base junction is reverse-biased [1], as it is in normal BiCMOS circuit operation [2], or when the device is exposed to ionizing radiation [3 - 5]. The damage typically leads to excess base current in the device, $\Delta I_{B}$, and no change in the collector current. Until now, authors have assumed that $\Delta I_{B}$ is caused primarily by interface states created during the stress [6 - 9]. The effects of net trapped positive charge, $N_{t x}$ have not been considered. Thus, the ef fects of $N_{o x}$ on the current gain of the device have not been identified.

In this work, the separate effects of $N_{o x}$ and surface recombination centers on the current gain of R.TTs are identified. It is shown that ionizing radiation causes a large increase in net positive oxide charge and a relatively small increase in surface recombination velocity. Hot electron stressing, on the other hand, causes a relatively small increase in net positive oxide charge and a large increase in surface recombination velocity. Since the current gain depends on the product of the two stressinduced defects, both types of stress can lead to qualitatively similar changes in the current gain of the device.

\section{Experimental Details}

The devices studied in this work are oxide-isolated polysilicon emitter bipolar transistors fabricated in a complementary bipolar processs closely related to that described in ref. [10]. A representative cross-section of the devices is shown in figure 1. Relevant structural information is summarized in table 1. For the irradiation study, the devices were irradiated with $10 \mathrm{keV} x$ rays at a dose rate of $1.7 \mathrm{krad}\left(\mathrm{SiO}_{2}\right) / \mathrm{s}$ up to a total dose of 1

'University of Arizona, Tucson, AZ

'Analug Devices, Inc., Woburn, MA

"Sandia National Labs, Albuquerque, NM

${ }^{\dagger}$ NSWC-Crane, Crane, IN

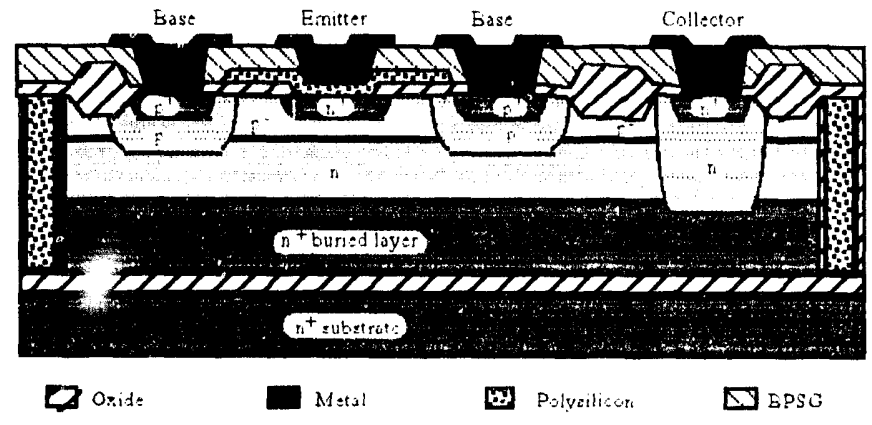

Figure 1. Representative cross-section of the devices studied in this work.

Table 1. Values of relevant device parameters.

\begin{tabular}{|r|c|c|}
\hline \multicolumn{1}{|c}{ Device Parameter } & \multicolumn{1}{c}{ Value } & \multicolumn{1}{c|}{ Units } \\
\cline { 2 - 3 } Emitter-Base Junction Depth & 0.3 & $\mu m$ \\
\cline { 2 - 3 } Intrinsic Base Surface Doping & $7.5 \times 10^{17}$ & $\mathrm{~cm}^{-3}$ \\
\cline { 2 - 3 } Oxide Thickness & 550 & $A$ \\
\cline { 2 - 3 } Emitter Size & $3 \times 3$ & $\mu m$ \\
\cline { 2 - 3 } Nommal Current Gidiu & 200 & $A / A$ \\
\hline
\end{tabular}

$\mathrm{Mrad}\left(\mathrm{SiO}_{2}\right)$. All pins were grounded during irradiation. For the hot electron stress, a constant reverse current of $6 \mathrm{~mA}$ was applied through the emitter-base junction of unirradiated devices for a total of 2048 seconds. A Hewlett-Packard $4145 \mathrm{~B}$ Semiconductor Parameter Analyzer was used for device characterization.

\section{Analysis}

The common-emittar current gain, $I_{C} / I_{B}$, is plotted versus baseemitter voltage, $V_{B E}$, in figure 2 for increasing values of stress. Figure 2 a shows the current gain for increasing values of total ionizing dose, while figure $2 b$ shows the current gain for increasing values of hot electron stress time. The current gain degrades substanlially for bolhtypes of stress, and the degradition is most severe at lower values of $V_{B E}$. Noye that the current gain degradation tends to saturate for lar fe values of total ionizing dose, but shows no tendency to sa urate for the stress times shown here. The trend, however, is qualittively simular 


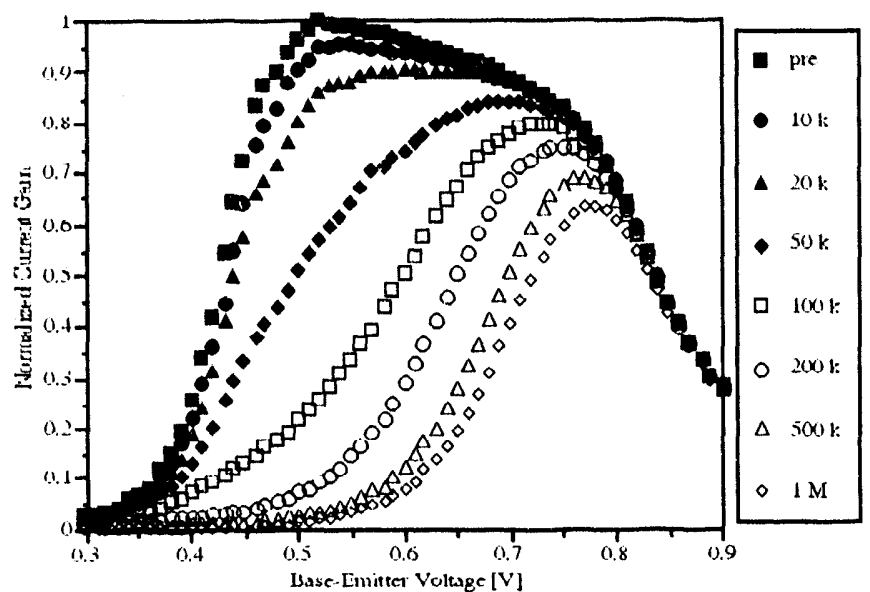

(a)

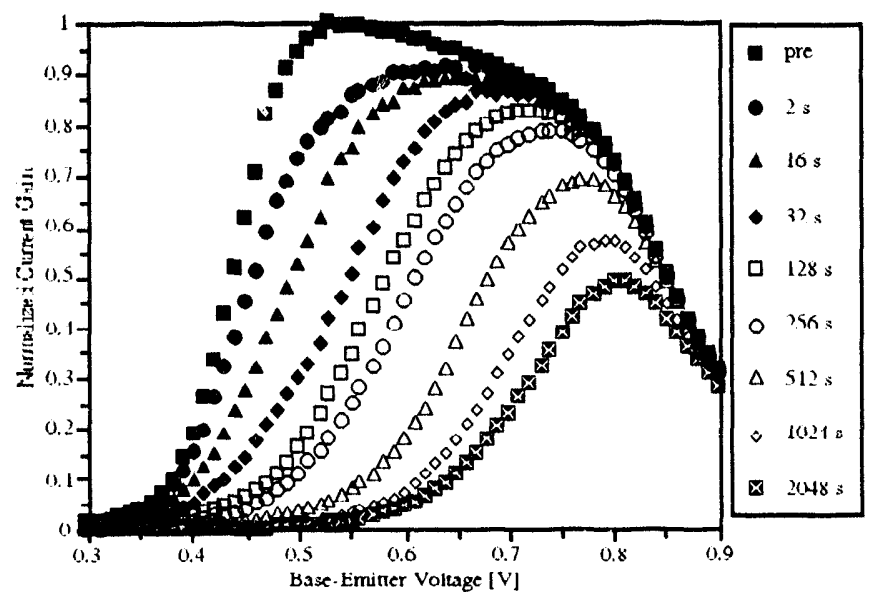

(b)

Figure 2. Common emitter current gain for increasing stress levels. a) Increasing total ionizing dose (units are $\operatorname{rad}\left(\mathrm{SiO}_{2}\right)$ ). b) Increasing hot electron stress time.

for both types of stress.

The collector current remains approximately constant throughout both radiation and hot electron stressing. The current gain (legrades because lie base currelll increases. The base currelll is written as $I_{B}=I_{B}$, pre $+\Delta I_{B}$, where the excess base current, $\Delta \Delta_{B}$, is recombination current in the emitter-base depletion region. The recombination current can be obtained analytically from Shockley-Read-Hall (SRH) recombination theory [11, 12]. Assuming equal electron and hole c:apture crosis-sections, a single trap level at midgap, and noderate forward bias, $\Delta I_{B}$ can be written as

$$
\Delta_{z}=\alpha v_{s u r r} \exp \left[\frac{\beta V_{v i E}}{2}\right] \gamma\left(N_{z}, V_{b E}\right)
$$

where $\beta=q / k l$ is the inverse thermal voltage, and ' 'surf $\alpha$, and $\gamma$ are given by

$$
\begin{aligned}
& v_{j u r}=\sigma v_{t i} N . \\
& \alpha=\frac{1}{2} q u, P_{E} \\
& \gamma\left(N_{b}, V_{B E}\right)=\int_{0}^{\dot{\psi}} \frac{c t y}{\cosh \left[\beta\left(\psi_{s}(y)-V_{B E}\right)\right]} \\
& +\frac{2 \pi}{P_{E}} \int_{0}^{r_{H}} \frac{r d r}{\cosh \left[\beta\left(\psi_{i}(r)-V_{k r} / 2\right)\right]}
\end{aligned}
$$

In these expressions, $v_{\text {surf }}$ is the surface recombination velocity, $N_{T}$ is the trap density, $\sigma$ is the effective capture crosssection, $v_{l h}$ is the thermal carrier velocity, $q$ is the electronic charge, $n_{i}$ is the intrinsic concentration, $P_{E}$ is the perimeter of the emitter, $y$ is the lateral position variable, $r_{B}=\sqrt{ } 2 y_{B}$, and $\psi_{s}$ is the surface potential.

The dependence of $\Delta I_{B}$ on surface recombination velocity is easily seen in equation (2): $v_{\text {surf }}$ merely scales $\Delta I_{B}$ multiplica-
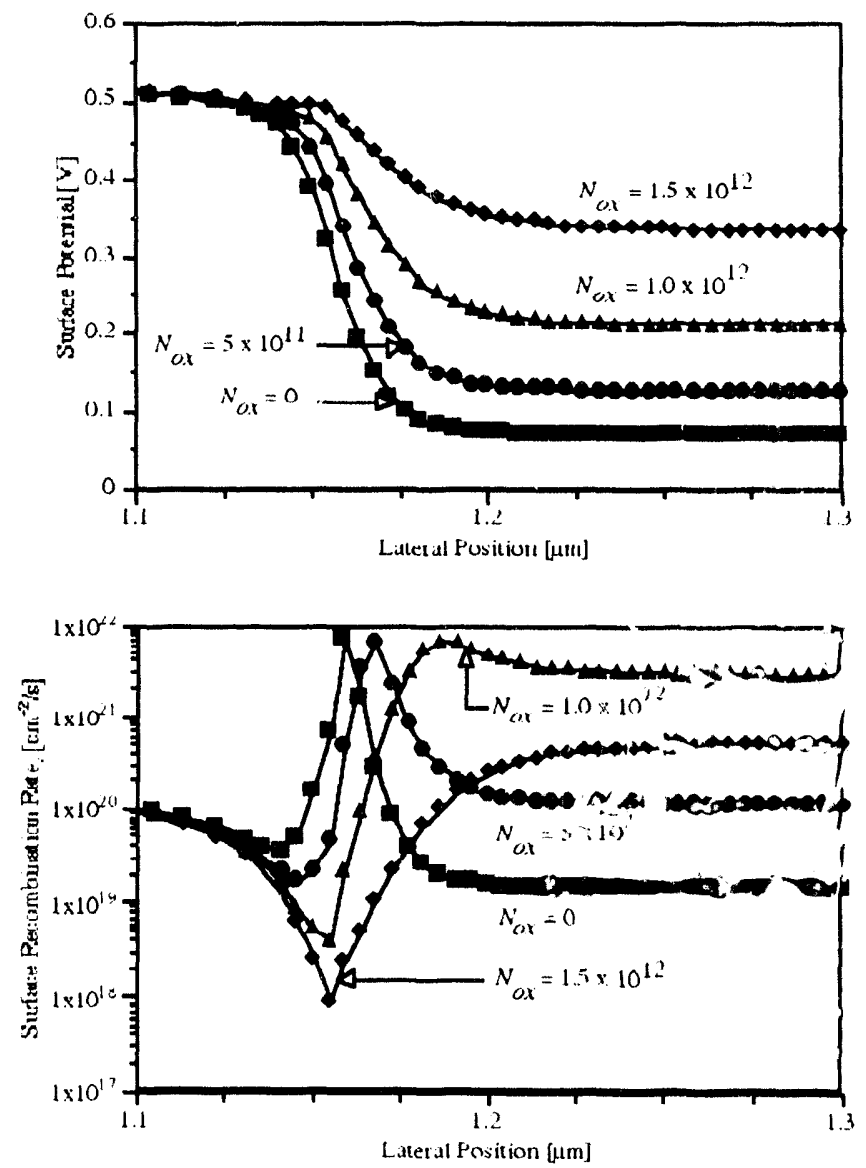

Figure 3. Surface potential (top) and surface recombination rate (bottom) versus lateral position, $y$, obtained from $S$ PISCES 2B simulations of the entter-base junction. The metallurgical junction is at $1.10 \mu \mathrm{m}$. After reference [5]. 
lively. The effect of positive oxide charge is not so easily seen. $T$ posilive charge affects $N I_{B}$ hy increasing the value of the $\gamma$ integral. This integral is seldom considered when analyzing recombination current, but it is crucial to take the contribution of this term into account in order to account for the effect of positive oxide charge. Positive charge raises the surface potenlial $\psi$ s in the base of the BJT. This increases the surface recomhination rate throughoui the base. In terms of the $\gamma$ integral, the integrand becomes a less sharply peaked function as uxide charge increases [5]. These trends are illustrated in figure 3, where PISCES-simulated surface potential and surface recombination rate are plotted versus lateral position for a fixed forward voltage and varying amounts of positive oxide charge.

Recombination current in $P N$ junctions varies as $\Delta_{B}=\Delta_{B}$ exp

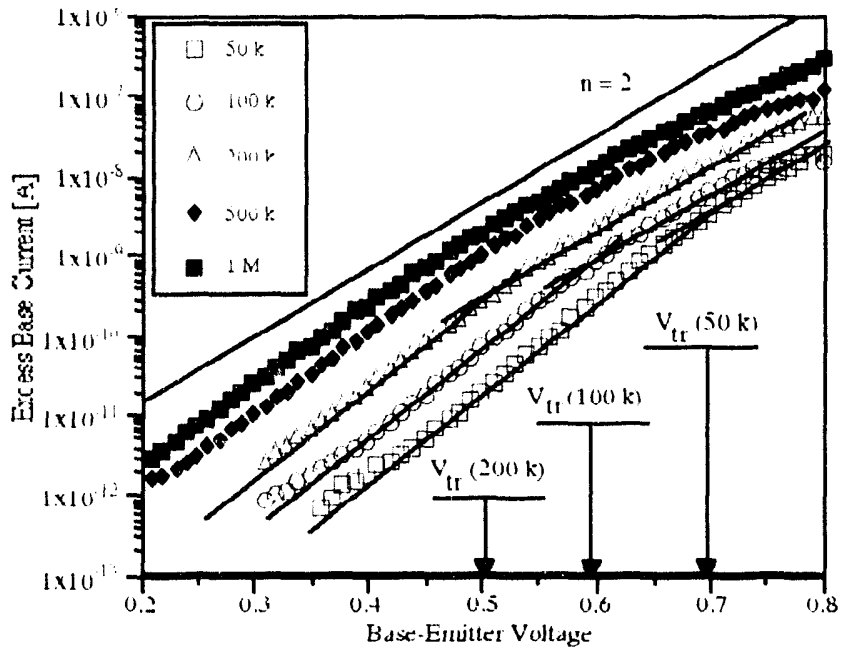

Figure 4. Excess base current versus base-emitter voltage for increasing values of total ionizing dose. The data correspond to those in figure $2 \mathrm{a}$.

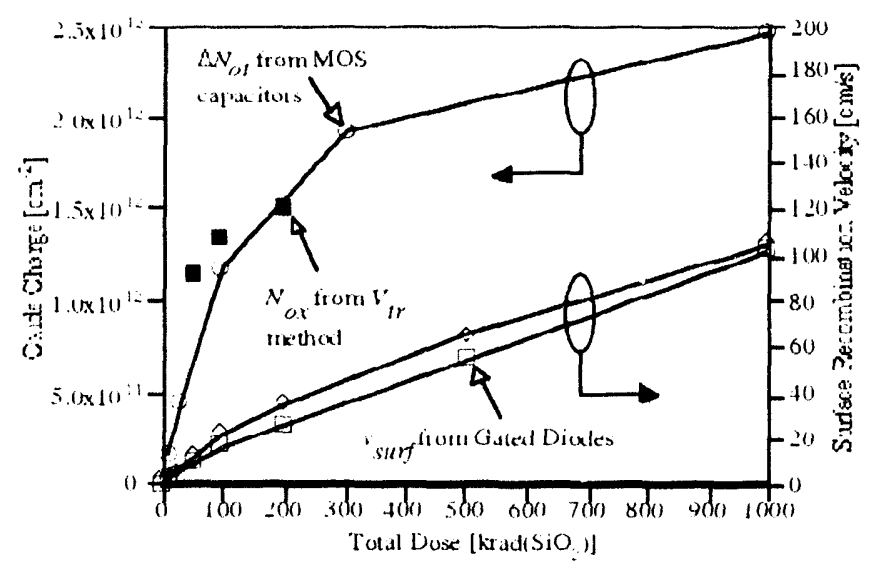

Figure 5. Ox ide charge and surface recombination velocity versus futal ionizing dose.

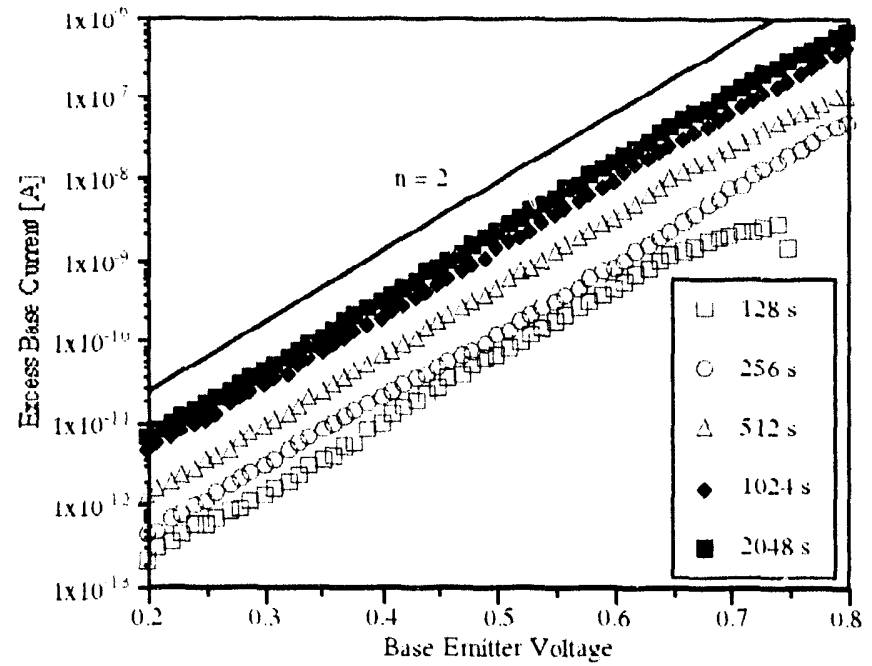

Figure 6. Excess base current versus base-emitter voltage for increasing values of hot electron stress time. The data correspond to those in figure $2 \mathrm{~b}$.

$[\beta V / n]$, where $n$, the ideality factor, depends upon oxide charge and forwardvoltage. The shape of the integrand in the $\gamma$ integral is what determines the ideality factor in the diode equation. In [5] it is shown that the value of oxide charge can be determined by plotting the excess base current versus base enitter voltage, as in tigure 4 . 'Three transition voltages, $V_{t r}$, are also identified. The transition voltages mark the transition between predoninantly surface and predominantly suhsurface recomhination. These transition voltages are readily related to oxide charge [5]. In figure 5, oxide charge calculated from the transition voltages is plotted versus total ionizing dose. Oxide-trapped charge, $N_{\text {or }}$ measured from MOS capacitors and surface recombination velocity measured from gated diodes from the same process is also plotted for comparison. It is seen that degrarlation due to ionizing radiation is caused by increases in both positive oxide charge and surface recombination velocity, in contrast to hotelectron damage, which is dominated by increas surface

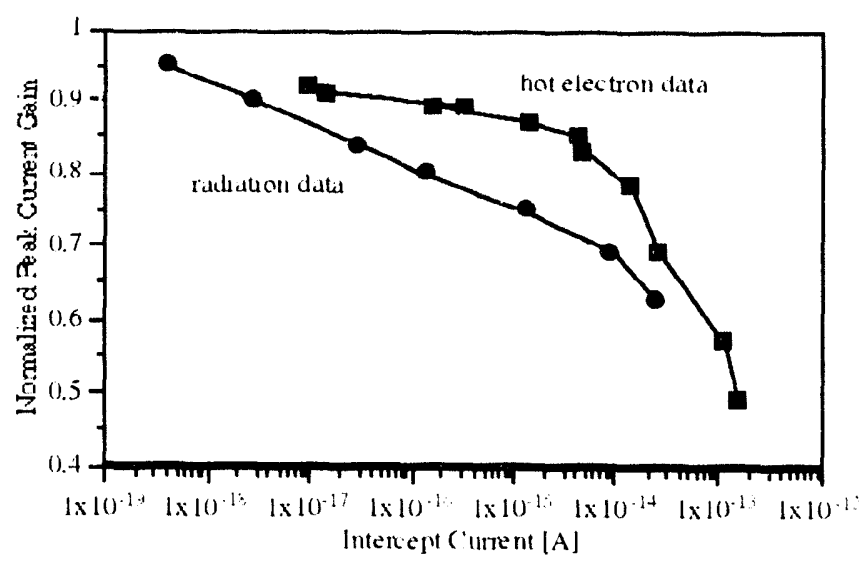

Figure 7. Nornalized peak current gain versus intercept current $N_{B_{1}}$ (a) $V_{s t}=0$ ) for radiation and hot electron stress. 
reconhination velucity.

In figure $6, \Delta_{B}$ is plotted versus $V_{B E}$ for several values of increasing stress time. The ideality factor is roughly two for all stress times, and no transition vollage can be determined for any stress level. This indicates that the maximum recombination rate is at the surface for all values of forward voltage, and thus that the oxide charge remains small for all stress times. This is the assumption made by several authors, but unt il now, no direct evidence of this was available.

Additional evidence for the existence of distinctly different defects for each type of stress is shown in figure 7, where the mormalized peak current gain is plotted versus $\Delta I_{B O}$. If the magnitudes of the stress induced defects were the same for both types of stress, these curves would lie on top of one another. The difference is a result of the large amounts of positive oxide charge induced in the oxide by the radiation stress. The curves apprach one antulher for large intercep' currents because the ideality factors for hoth types of stress are approximately two.

\section{Summary and Conclusions}

For hot electron stressing, the positive oxide charge remains small for all stress levels, indicating that the increase in base current is due primarily to increased surface recombination velocity. For radiation stressing, however, the increase in base current is due to both increased surface recombination velocity and increased positive oxide charge. The two types of stress lead to qualitatively sinular changes in current gain, although the individual contributions of surface recombination velocity and positive oxicte charge are different in each case.

The separate contributions of net positive charge and surface recombination centers are detected by plotting the excess base current as a function of forward-bias base emitter voltage. By graphically finding the transition from a diode ideality factor of two to an ideality factor less than two, the amount of oxide charge can obtained. The presence of oxide charge can also be detected by plotting the nor malized peak curent gain against the extrapolated intercept $\left(V_{\mathrm{BE}}=0\right)$ of the excess base current for both types of stress.

Despite the fact the radiation and hot electron stressing produce qualitatively similar changes in current gain, the magnitudes of stress-induced defects for each type of stress differ considerably. These differences must be laken inlo accoun when designing stress-tolerant processes and correlating hot electron and radiation stress results.

\section{Acknowled gments}

This work was supported by Sandia National Labs through their BMDO Oectron : $\mathrm{MOD}$ OIL program and by the Defense Nuclear Agency and Naval Surface Warface C'enter-Crame through a contract with Mission Research Corporation. The authors wish to thank Peter Winokur of Sandia National Labs, Dale Platteter of the Naval Surface Warface Center, Ron Pease of RLP Research, and Ken Calloway of the University of Armona for useful technical discussions. The experimental assistance of R.A. Reber, Ir. and L.C. Riewe of Sandia National Labs is gratefully ackinowledged.

\section{References}

1. B.A. McDonald, "Avalunche Degradation of hes" IEFETrans. Electron Devices, vol. ED-17, pp. \$71-87\$, 1970.

2. S.P. Joshi, R. Lahri, and C. Lage, "Poly Enitter Bipolar Hot Carrier Effects in an Advanced BiCMOS T'echnology." IELMM Tech. Digest. pp. 182-185, 1987.

3. R.N. Nowlin, E.W. Enlow, R.D. Schrimpt, and W.E. Combs, "Trends in the Total-Dose Response of Modern Bipolar Transistors," IEEE Trans. Nicl. Si. vol. 39, pp. 2020-2035, 1992.

4. E.W. Enlow, R.L. Pease, W.E. Combs, R.D. Schrimpf, and R.N Nowlin, "Response of Advanced Bipolar Processes to Ionizing Radiation." IEEE Trans. Nud. Si.., vol. NS-38. pp. 1342-1351. l(w) 1 .

5. S.L. Kosier, R.D. Schrimpi, R.N. Nowlin. D.M. Fleetwood, M. DeLaus, R.L. Pease, W.E. Combs. A. Wei, and F. Chai. "Charge Separation for Bipolar Transistors." to be published in IEEE Truns. Nuclear Science. vol 40.1993

6. D.D.-L. Tang and E. Hackbarth, "Junction Degradation in Bipolar Trunsistors and the Relidbility huposed Constraints to Sculing and Design." IEEE Trans. Eleciron Darices, vol. 35. pp. 21012107.1988

7. J.D. Burnett and C. Hu. "Modeling Hot-Carrier Effects in Polysilicon Eanitter Bipolar Transistors," IEEE Trans. Electron Devices, vol. 35. pp. 2238-22+4. 1988.

8. K.A. Jenkins, J.1). (ressler, and J.1). Warnock. "(Ise of ElectronBeam Irradiation to Study Performance Degradation of Bipolar Transistors After Reverse-Bias Stress," IEDM Tech. Digest. pp. 873-876. 1991

9. K.A. Jenkins and J.D. Cressler. "Electron Beam Damage of Advanced Silicon Bipolar I'ransistors and (ircuits,"IELM Tech. Digest. pp. 30-33.3. 1988.

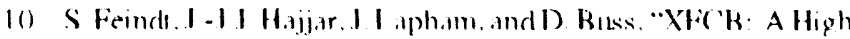
Speed Complementary Bipolar Process on Bonded SOI." BC TM Tech. Digest. pp. 264-267, 1942.

11. V.G.K. Reddi, "Intluence of Surface Conditions on Silicon Planar Transistor Current Gain," Solid-State Electron., vol. 10. pp. 30.5-3.34. 1967

12. A.S. Grove and D.J. Filzgerald. "Surface Eflects on p-n Junctions: Characteristici of Surface Space-Charge Regions Under Non-Eyuubrum Conditions," Solici-state Electron., vol. 9. pp. $783.806,1966$ 


\section{DISCLAIMER}

This report was prepared as an account of work sponsored by an agency of the United States Government. Neither the United States Government nor any agency thereof, nor any of their employees, makes any warranty, express or implied, or assumes any legal liability or responsibility for the accuracy, completeness, or usefulness of any information, apparatus, product, or process disclosed, or represents that its use would not infringe privately owned rights. Reference herein to any specific commercial product, process, or service by trade name, trademark, manufacturer, or otherwise does not necessarily constitute or imply its endorsement, recommendation, or favoring by the United States Government or any agency thereof. The views and opinions of authors expressed herein do not necessarily state or reflect those of the United States Government or any agency thereof. 

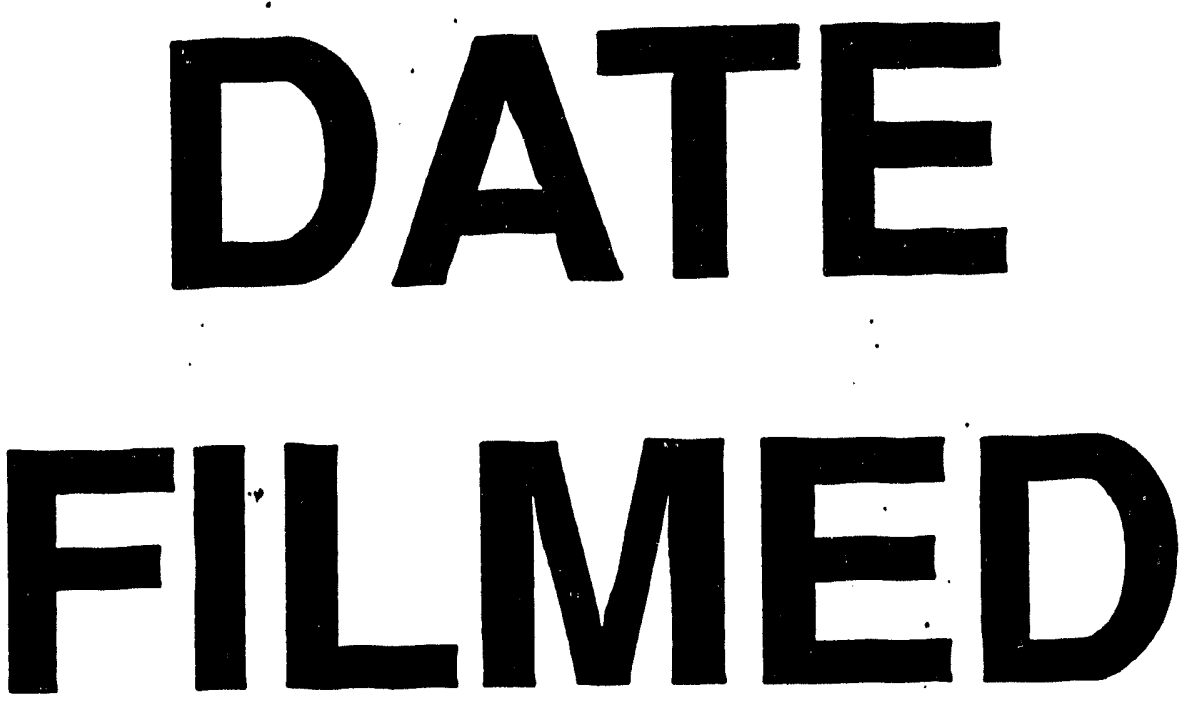

$2 / 4 / 94$
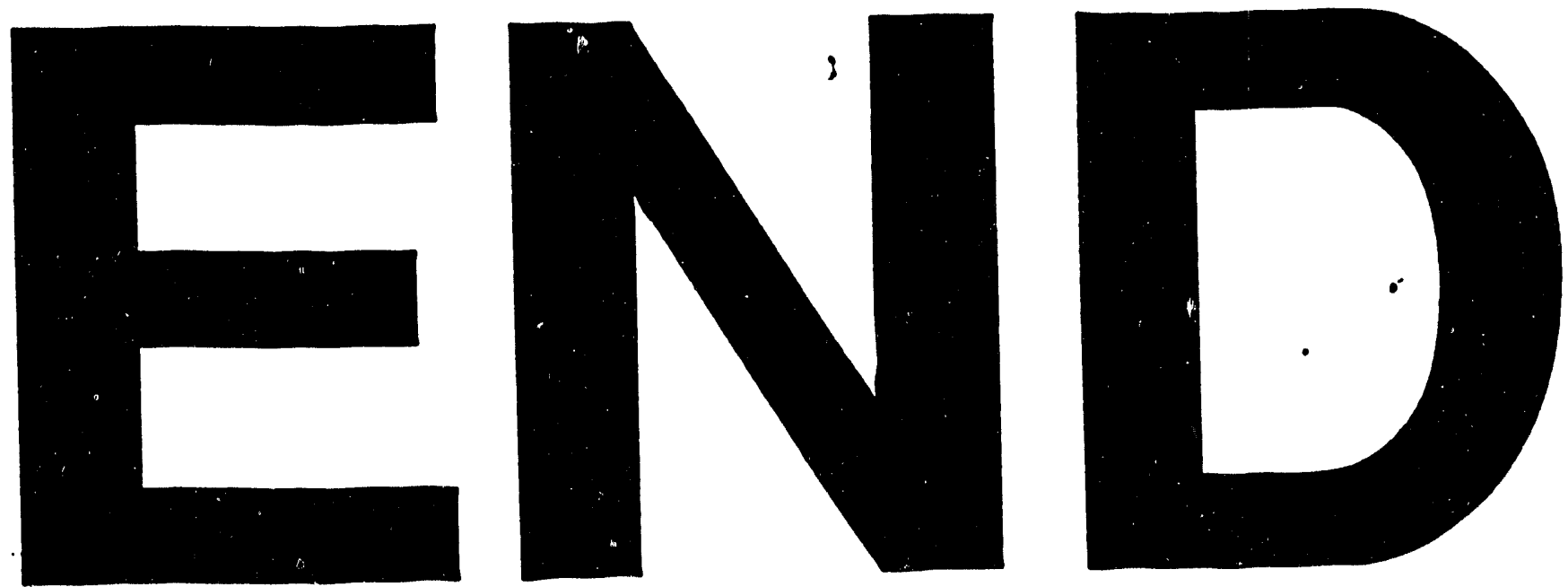
